\title{
A Hermeneutic of Variation? The Orthographic Variability of the Hebrew Bible and the Larger Dead Sea Scrolls
}

Johan de Joode

https://orcid.org/0000-0001-7209-880X

KU Leuven, Belgium

johan.dejoode@kuleuven.be
Dirk Speelman

https://orcid.org/0000-0003-1561-1851

KU Leuven, Belgium

dirk.speelman@kuleuven.be

\begin{abstract}
In this contribution, we investigate the distribution of variant spellings in the largest texts of the Dead Sea Scrolls and the Hebrew Bible using principles and methods from quantitative linguistics. The variability of spelling is widely accepted in the literature. To date, however, insight into the extent of said variability is limited. This article therefore quantifies orthographic heterogeneity within a corpus of Classical Hebrew using a computational approach. It introduces a measure for profile-based uniformity which has proven successful in variational linguistics. The aim is not to identify the causes of orthographic variation, but rather to investigate the phenomenon of variability in its own right. Understanding orthographic heterogeneity across texts influences historical reconstructions based on orthography, such as the use of orthography for the dating of texts, but it also affects the description of language change and the study of scribal practice.
\end{abstract}

Keywords: spelling; orthography; variation; heterogeneity; uniformity; quantitative linguistics 


\section{Introduction}

This contribution investigates the distribution of variant spellings in the largest texts of the Dead Sea Scrolls and the Hebrew Bible using principles and methods from quantitative linguistics. ${ }^{1}$ Its main topic is the extent of orthographic heterogeneity within documents. ${ }^{2}$ How much spelling variation can be found within the boundaries of individual documents? How uniform is a document's spelling?

\section{A Hermeneutic of Variation}

If there is one fact about the spelling of the Hebrew Bible and the Dead Sea Scrolls that is widely accepted in the literature, it is its variability. The centrality of variability in the scholarly literature on spelling can hardly be ignored: the documents are perceived to be highly heterogeneous in terms of their spelling. Regarding the Hebrew Bible, Barr $(1989,2)$ claims that "the variability of biblical spelling is one of its fundamental characteristics." He argues that the spelling of the Hebrew Bible is "consistently inconsistent" (Barr 1989, 2):

The obvious character of biblical spelling is its haphazardness. Consistency is at a discount, and variation at a premium. [...] The variations run across all books, all sources, all periods. Exceptions are not exceptional but are the normal thing. (Barr 1989, 202-3)

The very title of Barr's monograph, The Variable Spellings of the Hebrew Bible, asserts that orthographic variability is an important characteristic of Classical Hebrew. Tov claims that spelling homogeneity is not a preoccupation of the ancient authors, editors, and scribes: "We all know there is no consistency, but nevertheless in our analysis of the ancients we often act as if they embraced that ideal. [...] I suggest that consistency was not part of their world" (Tov 2015, 36). For the scrolls, Ulrich $(1990,32)$ observes that despite certain more consistent manuscripts, there is "for many manuscripts [...] no consistent system of orthography." Tov's insights regarding Qumran scribal practice to a large extent depend on orthographic and morphological features, yet he is repeatedly

1 The present contribution is the second of a two-part study of linguistic variation. The first article was published in this journal under the title "Digital Masorah: Toward an Index of Orthographic and Morphological Variation at the Lexical Level" (de Joode, 2020). The research for this article was conducted as part of the project A Corpus Linguistic Approach of Classical Hebrew: A Pilot Project (3H160213, KU Leuven, with as principal investigators Eibert Tigchelaar and Pierre Van Hecke).

2 The term document is an abstract label for an entity that in modern times can be perceived as a textual unity regardless of its compositional character or its transmission history. It is a technical term that is purposefully flexible: First Samuel, for example, is treated as a single document in this study, although it could be argued that it is not a composition as such (being part of Samuel). Future studies could consider First Samuel and Second Samuel as a single document. The term document is preferred over alternatives such as composition or text because text could also refer to the surface text as found in a specific manuscript and because the boundaries of compositions are disputed. 
criticised because these features are too inconsistent. ${ }^{3}$ In relation to a number of peculiarities in the community scrolls, Reymond $(2018,254)$ states, "Why such characteristics would not be found consistently throughout the texts that this scribe copied is hard to answer and remains an open question."

Despite the widespread acknowledgement of the variability of spelling in the Hebrew Bible, several protagonists highlight the remarkable orthographic consistency of specific cases. Andersen and Forbes $(1986,331)$ stress the homogeneity of certain document portions when investigating their spelling types. Tov $(2008,16)$ observes the ambivalence in Barr's remarks who highlights how variable the spellings are, while also extracting consistent patterns: "one can probably accommodate both an assumption of inconsistency in general and the consistent behaviour of certain words and patterns. In a way, however, judgment should be delayed until each of the books of MT is discussed separately and thoroughly."

In the work of Andersen and Forbes and in that of Barr there are details that hint at stable orthographies. Andersen and Forbes (1986, 214-39) evaluate whether there are "possible confounding factors" such as proximity or frequency that could influence spelling choice besides the variables they primarily focus on (which include stress, text portion, and vowel type). In their analysis, the authors count the number of discordant spellings of lexemes that are repeated within a span of roughly two verses. Their findings illustrate how lexemes that are repeated in the same, small literary context in the vast majority of the cases display concordant spellings. On average, $4.7 \%$ of spellings are discordant when they are repeated within "39 or fewer intervening segments," with no effect of the size of the window of words between the two repeated lexemes (Andersen and Forbes 1986, 214). These findings are interesting as they suggest, albeit in embryonic form, that there might be an effect of "lexical selectivity" (Barr 1989, 36) or "word-level conditioning" (Andersen and Forbes 1986, 271) that influences spelling choice also for non-fixed spellings. What Andersen and Forbes (1986, 153) declare as fixed, however, is not necessarily fixed when the Dead Sea Scrolls are part of the corpus (for instance, the spellings of אלהים or כל כל כersen and Forbes do not attempt to establish an understanding of the variation at the level of lexemes; they want to ascertain that the repetition of a lexeme in the immediate vicinity of itself does not influence its spelling choice more than the factors they propose. To a certain extent, the present paper studies their question at scale: how uniform are documents when their spelling preferences are measured in terms of lexical selection within documents as a whole, and not within small windows of text with repeated lexemes.

3 For a discussion of these critiques, cf. Tigchelaar (2010, 179-80). On the role of "scribal individuality" in light of the inconsistency of the features proposed by Tov, cf. Zahn $(2018,202-203)$. 


\section{Research Questions}

In light of both the overall variability of spelling and the perceived stability of certain spellings described above, spelling variability should be measured in its own right, and not in an attempt to describe the forces that trigger linguistic variation. The goal of what follows is to describe the larger tendencies and not the details of the variation. The leading questions are the following. How much variation would one expect in a single composition? Are there documents that vary more extensively than others? How uniform is the spelling of individual documents? In order to answer these questions multiple methodological issues should be tackled, many of which require detailed discussion. Measuring orthographic homogeneity is not a straightforward process. The methodological choices one makes heavily impact the outcome of the experiment. The next section therefore focuses on introducing a viable method to extract a sample of spelling variation.

The wealth and diversity of spelling variants within the boundaries of individual documents, paragraphs, and even within a few verses or lines is significant. For every example of inconsistency, however, a counterexample can be found that shows how uniform that very example is in another context: for instance, in Jeremiah the alternation between לוא respectively represents 479 and 34 counts, but the same variants are attested respectively 333 times and only once in the Psalms. ${ }^{4}$ To be sure, it seems there is not a single fully consistent document in the corpus of Classical Hebrew that is of any length, yet that is not necessarily a phenomenon limited to ancient Jewish documents. Given the perception of heterogeneity, the remarkable homogeneity of certain lexemes, and the methodological benefit of understanding variability, this study wants to take a first step towards the quantification of spelling variability. Is spelling indeed as inconsistent as one is led to believe based on individual spelling choices? Can orthographic uniformity be measured and are there measurable differences between the orthographic consistency of individual documents? This article takes a comparative approach, viz. the variability is compared across documents. The added value of understanding the (in)consistency of individual documents is the set of new questions it raises. To what extent does spelling reflect the transmission history of a document (Andersen and Forbes 1986, 315)? Are documents that emanate from different sources, or documents with many different sources, more heterogeneous in terms of their orthography? Can one distinguish a document's alternative spellings from its preferential spellings? Which spelling profiles are heterogeneous despite occurring in a document that is relatively homogeneous when it comes to spelling? What makes these spellings differ from the majority spellings in the document?

4 All counts are based on a database that was exported, adapted, and enriched from Accordance 11.2.5. Small divergences in counts are possible. 


\section{Corpus}

In the case of Classical Hebrew, the extant corpora are very different: the Hebrew Bible is essentially a medieval corpus taken from a single manuscript, and the Dead Sea Scrolls are a set of ancient documents composed of fragmented documents and compositions. Is the orthography of these documents comparable? It is unclear what one should expect. Would the spelling of the medieval corpus have been harmonised over time? Or do they display a mixture of older and younger spellings as later scribes updated spellings to match later spelling practice? In light of the variety of questions raised above, the present contribution is limited in its scope. Not only do corpus-wide treatments of orthography in the Hebrew Bible or the Dead Sea Scrolls tend to fill books rather than articles, the variation within the corpora of Classical Hebrew is at times so complex that only introductory matters will be addressed here. ${ }^{5}$

\section{Document-internal Uniformity}

The spelling index and the spelling matrix described in de Joode (2020) make it possible to start answering the aforementioned research questions. ${ }^{6}$ This section investigates whether the documents in the corpora under scrutiny differ when it comes to their variability. Answers to these questions could increase our insight into the extent of the orthographic variation and the distribution of the phenomenon.

In order to answer these questions based on quantitative measures a number of different, relevant frequencies should be introduced. The length of a document affects the expected frequency counts of variables for the given documents. In simple terms, if a document contains 5000 tokens, and a variable occurs five times, this differs from a profile with five occurrences in a document with 15000 tokens. This can be remedied by using relative frequencies, viz. frequencies that take the length of a document into account by transforming the absolute frequency into a proportion of the tokens in a given document. In this case, three different types of relative frequencies are relevant: a) the frequency of a variant in proportion to the total number of tokens in the document, b) the frequency of a profile in proportion to the total number of tokens in the document, and c) the relative frequency within a profile or the proportion of tokens within a variable that is expressed by a variant. An example based on Table 1 suffices. If 11Q19 counts 9065 tokens excluding reconstructed and edited forms as well as a number of

5 The definition of what makes a document is taken from Accordance, meaning that First Kings and Second Kings are treated as separate documents, despite the fact that they might not have been transmitted as such. In the case of the larger two-part documents this is not a problem as gaining insight into the variability of First and Second Samuel, for instance, is valuable in its own right. The smaller documents such as the Minor Prophets are not merged into a single document as the resulting measure for uniformity would be composite and ambiguous.

6 For the purposes of the present inquiries the index is filtered in order to remove morphological variations and minor mistakes. 
special cases, a) the relative frequency of the variant זואת is $16 / 9065$ or 0.0017 , b) for the entire profile זהת as adjective feminine singular in the absolute state the relative frequency is $(16+1+1) / 9065$ or 0.0019 , and c) the relative frequencies for the variants within the profile are $16 / 18(0.88), 1 / 18(0.055)$, and $1 / 18(0.055)$. The difference between the relative frequency of a profile and a variant is often, but not always, negligible. The sum of the relative frequencies in a document or a profile is 1 . The relative frequency as related to the document size differs substantially from the innerprofile relative frequency which reflects the distribution of the variation within a profile regardless of the size of the document. This last measure will be instrumental for measuring document-internal orthographic uniformity.

Based on a spelling matrix (such as Table 1), the uniformity of a profile can be quantified by a single numerical value. Inner-profile relative frequencies reflect the uniformity of a single profile but provide us with multiple values per profile: a spelling profile with two variants, one occurring eight times, the other twice, will yield the innerprofile relative frequencies of 0.8 and 0.2. More complex profiles such as three variants occurring five times, once, and once, still yield relative frequencies (in this case 0.71 , 0.14 , and 0.14). These relative frequencies obscure the absolute frequencies of the spelling profile, but they do allow us to study how much of the profile the preferential variant accounts for, and the same for non-preferential variants. In the first example, 0.8 and 0.2 , the relative frequencies indicate that one of the variants is used in the majority of the cases, whereas the other only represents a smaller fraction of the variation. The second example, $0.71,0.14$, and 0.14 , still has a dominant variant, but the variation is spread over three rather than two variants in the document at hand. Based on these relative frequencies, it is possible to gain insight into the tendencies within a document, but it would be preferable to obtain a single value to represent the document-internal uniformity of a profile, ideally a value that takes both the relative frequencies as well as the number of variants within the variable into account.

To compute the uniformity of a spelling profile for a document, one can apply a simple formula to the relative frequencies for each individual spelling profile in a document. We propose adapting a measure for internal uniformity because it is a straightforward, yet powerful measure used within variational lexicology and dialectology (Daems, Zenner, and Geeraerts 2016, 286; Geeraerts, Grondelaers, and Speelman 1999, 46). ${ }^{7}$ It can be used, for instance, to quantify whether a specific language variety prefers a different lexical realisation of a concept than another language variety. The principle is straightforward: take the sum of each of the respective relative frequencies to the power of two within a profile. For instance, the absolute frequencies 99 and 1 yield a high uniformity of $0.992+0.012=0.98$. By way of comparison, if the absolute frequencies within a profile are 94 and 6 for one profile, and 94,3, and 3 for another, the respective uniformities are $0.942+0.062=0.8872$, and $0.942+0.032+0.032$ or 0.8854 . This

7 For a related measure, cf. Speelman, Grondelaers, and Geeraerts (2003). 
single value for uniformity has the advantage that it not only captures differences in relative frequencies, but it also captures the number of variants in a profile. A profile with variant frequencies of 4 and 2 yields a uniformity of 0.55 , but if there are three variants, say 4,1 , and 1 , the uniformity is 0.5 . In other words, the more variants in a profile, the lower its uniformity; the larger the difference between the relative frequencies, the lower the uniformity. Capturing the variability of a profile into a single value enables the comparison of the uniformity of profiles, and by extension the uniformity of documents. An aggregate value for spelling uniformity is obtained by taking the mean of all the profiles with variation in that document.

This metric captures the variability of spelling at the level of individual profiles. It indicates how much the variants differ in terms of their frequency and whether a profile has many different variants or only a single one. In the latter case, that of a profile with a single variant, the uniformity is 1 . If a profile has only two equally frequent variants the uniformity is 0.5 . If it has three equally frequent variants, which is not a common phenomenon, it is 0.33 . These examples are cases where a profile does not have a preferential variant. The measurements for uniformity range between just above zero to one; the higher the value, the more uniform the profile. Table 2 illustrates orthographic uniformity as applied to the sample provided in Table $1 .{ }^{8}$

8 If a profile only has a single occurrence, it can by definition not show any variation and hence it is excluded from Table 2. For this example, this means that ראוש in 11Q19, בשר in 11Q5, and ראש in Mur 88 are disregarded. 
Table 1: Sample of a spelling matrix

\begin{tabular}{|c|c|c|c|c|c|c|c|c|c|c|}
\hline & & 11Q19 & $11 Q 5$ & $1 Q 8$ & $1 \mathrm{QH}^{\mathrm{a}}$ & 1QIsa'_I & 1QIsa'_II & $1 \mathrm{QM}$ & $1 Q S$ & Mur88 \\
\hline \multirow{4}{*}{ AFSA } & זאות| & 1 & & & & 3 & & & & \\
\hline & זאת & 1 & & 5 & 2 & & & & & 5 \\
\hline & זואת & 16 & 2 & & & 23 & 13 & & 1 & \\
\hline & זות & & & & 4 & 2 & & & 3 & \\
\hline \multirow[b]{2}{*}{ NCMSA } & בסר & & & & 1 & & & & & \\
\hline & בשר & 3 & 1 & & 20 & 7 & 4 & 4 & 2 & \\
\hline \multirow{3}{*}{ PC } & כי & 71 & 83 & 61 & 94 & 128 & 2 & & 1 & 32 \\
\hline & כיא & 2 & & & 38 & 83 & 112 & 24 & 33 & \\
\hline & כיה & & 1 & & & & & & & \\
\hline \multirow{4}{*}{ NCMSA } & ראוש & 1 & & & & 3 & & 1 & & \\
\hline & ראש & & & & & 1 & & 3 & & 1 \\
\hline & רואש & & 2 & & & 2 & & 2 & & \\
\hline & רוש & & & & & 2 & & & & \\
\hline
\end{tabular}

Table 2: Sample of document-internal spelling variation

\begin{tabular}{|c|c|c|c|c|c|c|c|c|c|}
\hline & 11Q19 & 11Q5 & $1 Q 8$ & $1 \mathrm{QH}^{\mathrm{a}}$ & 1QIsa' & 1QIsa'_II & 1QM & 1QS & Mur88 \\
\hline AFSA זואת-AFSA & 0.79 & 1 & 1 & 0.55 & 0.69 & 1 & & 0.63 & 1 \\
\hline בשר-NCMSA & 1 & & & 0.9 & 1 & 1 & 1 & 1 & \\
\hline -PC & 0.94 & 0.97 & 1 & 0.58 & 0.52 & 0.96 & 1 & 0.94 & 1 \\
\hline ראש-NCMSA & & 1 & & & 0.28 & & 0.38 & & \\
\hline
\end{tabular}

The names of the profiles are based on the data available in the database (de Joode 2020): the lemma and the morphological parsing are taken from Accordance and no significance should be attached to the selection of which variant (זואת ואת , for instance) is used in the label for the profile. The "ones" in Table 2 indicate complete uniformity, yet the nulls, or the empty cells, signify the absence of a value for that profile in the given document. These nulls should not be mistaken for zeros. This is significant as it is impossible for a profile to have 0 uniformity. This matrix, at least when considered in its entirety and not just the sample here, provides a snapshot of the orthographic variation in the corpus. The data points for these four profiles in these nine varieties can be compared in two directions, viz. the columns and the rows. At the level of the profiles, reading the rows horizontally, בשר-NCMSA is almost completely uniform, כי-PC is highly uniform is some documents, but not in all. When reading the matrix vertically, one can gain insight into the orthographic uniformity of the documents. In this example, Mur 88 and 1Q8 are fully uniform, which cannot be said 
of the Hodayot. 1QIsa ${ }_{-}$II is decidedly more uniform for these profiles than 1 QIsa ${ }_{-}{ }_{-}{ }^{9}{ }^{9}$ Whereas the results of these exploratory analyses on only four profiles aids to explain the method, it should be noted that the analyses to follow handle many hundreds or even thousands of profiles at once.

Understanding orthographic uniformity across many hundreds of profiles is not possible through manual inspection, as the human mind cannot synthesise such levels of complexity with many profiles in many documents. The uniformity of all spelling profiles in a document can therefore be transformed into an aggregate value by taking the mean of the profile-based uniformities in a given document. This mean per document indicates a document's consistency or inconsistency. This value elucidates whether all documents display a similar form of variability. In what follows, we discuss a number of closely related experiments targeted at providing insight into the average uniformity of the documents. This type of analysis is not characterised by a single methodology that, once discovered, provides deterministic results regardless of the ways in which it is applied. The exploratory analyses presented below aim to discover the general tendencies in the data regardless of the methodological choices that affect the results.

Before presenting the mean uniformities per document, it is necessary to select a smaller number of profiles that will be used for our analysis. In an ideal scenario, the mean uniformity could be computed using all the profiles extracted from all the documents, but this solution would be sub-optimal for two reasons: a) there are mistakes in the morphological parsing (for instance, the conjunction 1 has two variants in the Psalms); these mistakes can have unintended effects if every profile in every document is taken into account, and b) these mistakes require manual verification and there are too many profiles to verify them all manually.

Hence the following filters are applied to the spelling matrix in order to limit the effect of errors related to the morphological parsing and the transcription of the text, as well as idiosyncratic scribal errors, and a small number of mistakes with Qere/Kethib forms that stem from the alignment of the Accordance data with the data from the Eep Talstra Centre for Bible and Computing (for more information, see de Joode 2020). Firstly, we only keep variants that occur in at least two of the documents, dismissing any variant that is unique to a single document regardless of how many times it occurs in that single document. ${ }^{10}$ This does not mean that a spelling profile is discarded when a variant unique to a document is found: this selection takes place at the level of the variants and not the variables. This filter is required because the selection of spelling profiles does not only affect the measurement of the uniformity of the document in which the variant

9 In this contribution, we regularly split 1 QIsa ${ }^{\mathrm{a}}$ into two separate documents, viz. 1QIsa ${ }_{-} \mathrm{I}$ (cols.1-27) and $1 \mathrm{QIsa}{ }^{\mathrm{a}}$ _II (cols. 28-59); we do so in order to reflect the scholarly observations regarding the "large gap at the bottom of col. 27" (Giese 1988, 61).

10 In stylometry this type of document frequency filter is termed culling. 
is found. For example, if there is a mistake in the data that affects a high-frequency item with by definition a fixed spelling (such as the preposition ב), the unintended effect of that error is that the average uniformity of all documents containing the preposition would be increased. In other words, this type of minimal document frequency filter finds the equilibrium between capturing all the variants in a document and limiting the effect of non-essential idiosyncrasies. The subset of profiles with variants shared by at least two documents suffices to provide a solid, initial indication of the degree of orthographic heterogeneity.

Secondly, any cell in the matrix that satisfies the following condition is replaced by null (not zero, but an empty cell): a profile that has only a single variant which occurs only a single time in a variety. These variation counts are removed within that specific document because variation is per definition not possible if a profile does not at least have two occurrences in a document. In the latter case it is the equivalent of a spelling hapax legomenon within the boundaries of the given document.

Thirdly, after the above restrictions, we only keep profiles that still actually have variation (>1 variant). We also remove ca. 120 profiles manually which upon inspection do not contain orthographic variation. Finally, we compute the average uniformity keeping the fully uniform profiles (uniformity $=1$ ) in the counts for any profile that satisfies the above conditions. The absolute frequencies of the profiles do not influence the weight of a profile for measuring the mean uniformity, which therefore implies that the impact on the mean is identical regardless whether the profile represents 100 or only two tokens in the document. Figure 1 displays the results. 
Results

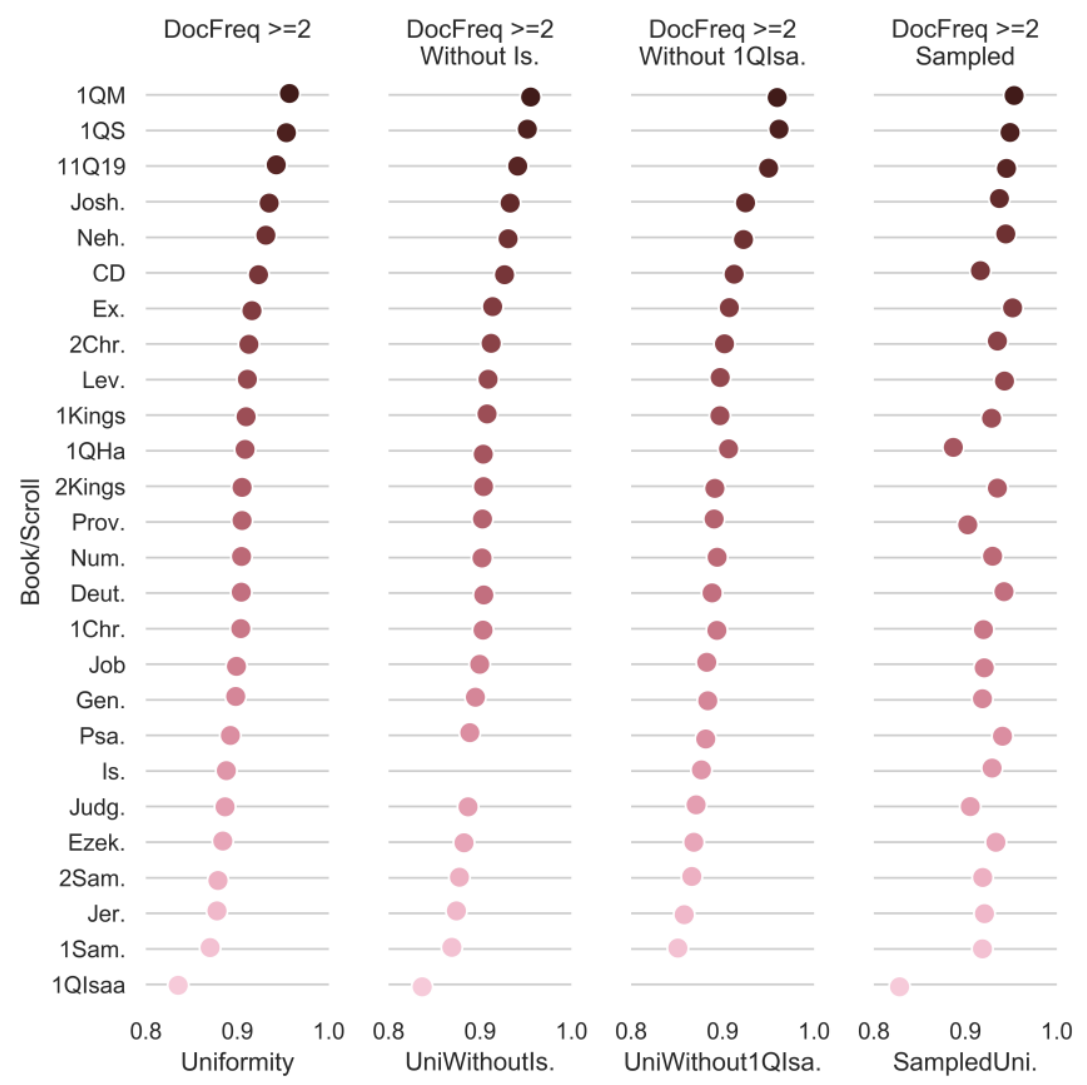

Figure 1: Mean uniformity per document, four panels, from left to right: a) the mean uniformity of all profiles that pass the filter, b) idem without Isaiah, c) idem without $1 \mathrm{QIsa}{ }^{\mathrm{a}}$, d) mean uniformity based on sample documents of equal length

The average orthographic uniformity for our corpus is 0.90 with a minimal value of 0.835 for $1 \mathrm{QIsa}{ }^{\mathrm{a}}$ and a maximum value of 0.956 for $1 \mathrm{QM}$. Given the restrictions applied above, it should be stated that the average uniformity of our documents is relatively high. The mean uniformity would be even higher if all profiles with fixed spellings were included. These results confirm Barr's intuition that lexical selection might govern —or at least affect - spelling choice. The numerical values are not the primary source of information, but the ranking is, notably at the extremities of the scale. Despite many opportunities to use variant spellings, the overall picture does not suggest that spelling choice is haphazard. If that were the case, the mean uniformity would be closer to 0.5 or even lower for profiles with multiple variants.

The most incongruous document is 1 QIsa ${ }^{a}$. This document is distinctly less uniform in its spelling than the other documents, which together form a continuum between the 
extremes of homogeneous and heterogeneous spelling practices. Interestingly, when 1 QIsa ${ }^{a}$ is split into two parts, both parts exhibit a distinctly less uniform orthography than the other documents in the corpus.

Because there is no baseline of the expected uniformity of a document, Figure 1 can only be interpreted in relation to itself. One could wonder whether the presence of two copies of Isaiah does not create a bias in the dataset, especially when the minimal document frequency for a variant is two and variants found in Isaiah could hence more easily become part of the sample of variables. To test this intuition, the uniformity is measured for the corpus when excluding $1 \mathrm{QIsa}{ }^{\mathrm{a}}$ on the one hand, and Isaiah on the other. In this particular case, the removal of one of either $1 \mathrm{QIsa}{ }^{\mathrm{a}}$ or Isaiah does not yield important changes at the extremities of the ranking as the shape of the second and third panel are highly similar to that of the first panel. This is a good sign for the representativeness of our method. The composition of our corpus to a certain degree influences the analysis: when measuring a linguistic variable across the documents in a corpus, the selection of the documents affects the eligibility of our variable. For instance, when $1 \mathrm{QIsa}{ }^{\mathrm{a}}$ is excluded, $1 \mathrm{QH}^{\mathrm{a}}$ is slightly more uniform. This could be explained by the fact that $1 \mathrm{QH}^{\mathrm{a}}$ might have more spellings in common with the scrolls than with the Bible. In these cases, the inspection of the actual profiles in the spelling matrix can provide more insights. Interestingly, there are cases where Isaiah is not uniform, but $1 \mathrm{QIsa}^{\mathrm{a}}$ is. These have been studied at great length in the literature, but a few pointers are worthwhile: the object marker with a light suffix is less uniform in Isaiah, and in its spelling of certain suffixes 1 QIsa ${ }^{\mathrm{a}}$ is more systematic in its use of a yôd to bind the headword to the suffix. Isaiah is not uniform for the negative particle לאי 1 QIsa ${ }^{a}$ is (with vowel letter) and for מיא מי the inverse is the case.

The documents in our corpus have different lengths. These differences affect how much variation can be found in a document: the longer a document, the higher the probability a token is repeated, and hence the higher the probability of variation. It should, however, be hypothesized that documents such as $1 \mathrm{QS}$ and $1 \mathrm{QM}$ are more uniform because they are shorter. Therefore, the relation between document length (in number of tokens) can be plotted over and against spelling uniformity (Figure 2). The resulting picture indicates that there is a weak correlation between document size and uniformity; but, given the number of cases where this does not hold (cases above and below the regression line), this is not indisputable. 


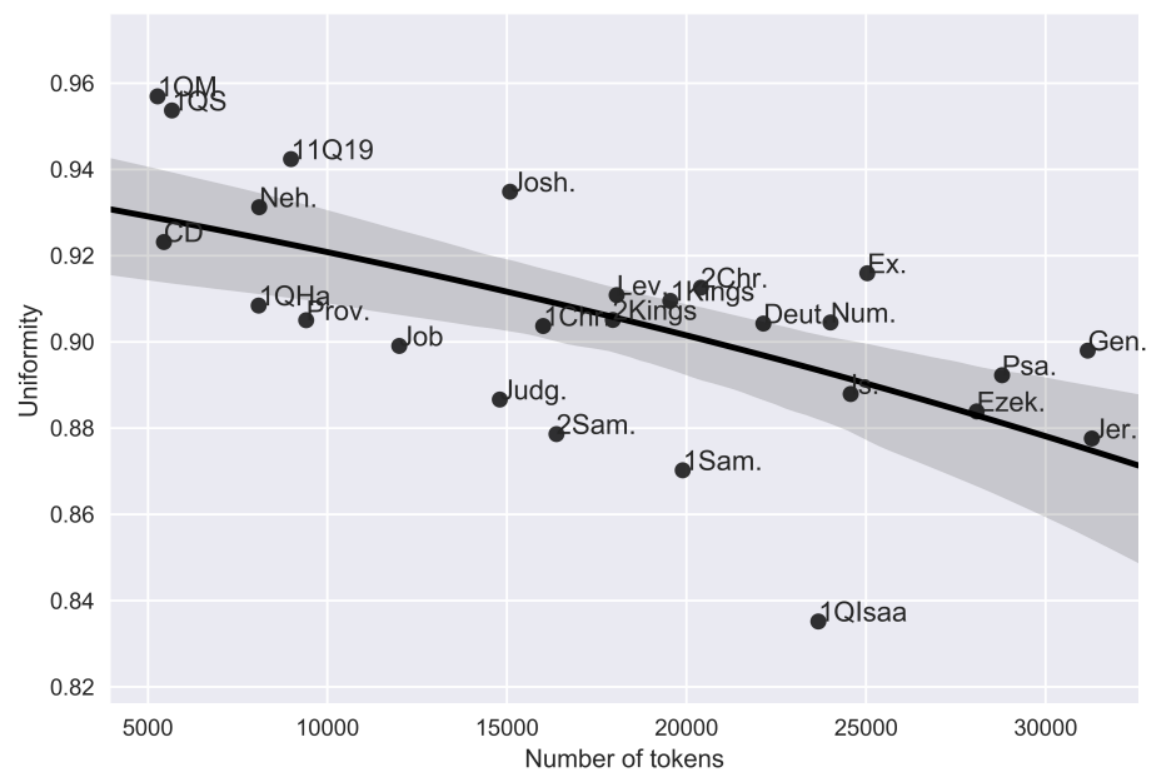

Figure 2: Evaluating the effect of document-length on mean uniformity

It is nonetheless worthwhile to investigate whether shorter documents such as $1 \mathrm{QS}$ and $1 \mathrm{QM}$ remain distinctively uniform if their length is artificially limited. This experiment is sub-optimal compared to the main results presented above because artificial shortening limits the available data to such an extent that the internal ranking of the documents can hardly be trusted. Nonetheless, if the shorter documents are still perceived as highly uniform, one could argue that they are genuinely more uniform than the others, regardless of their shorter length. In order to shorten the documents and measure their uniformity, we sampled 5000 tokens without replacement and computed the uniformity of these samples using the same restrictions as those applied above (minimal document frequency $=2$, minimal number of occurrences for an entire profile in a book $=2$, exclude profiles which do not match these settings). Because the sampling of the document makes the process sensitive to random errors, we have repeated this entire process fifteen times and have then computed the average of these runs. ${ }^{11}$

The results of this procedure can be found in the fourth panel (on the right) of Figure 1. The results are too fragmentary to study the rankings of the documents near the centre of the scale. Indisputably, 1QIsa ${ }^{a}$ stands apart from the other documents in terms of its

11 The mean used for these analyses is not weighted because the relatively fixed spelling of high frequency items could easily outweigh the importance of the variation attested in lower-frequency items. 
heterogeneity. This remains true when 1 QIsa ${ }^{a}$ is split into two parts: both parts are highly heterogeneous $(0.813$ and 0.885$) .{ }^{12}$ These results are in line with the attention that is given in the literature to the orthographic peculiarities of 1QIsa ${ }^{\mathrm{a}}$ in particular and the Dead Sea Scrolls in general (Qimron 1986, 17-24; Reymond 2014, 23-64). At the other end of the spectrum, 1QM and 1QS remain highly homogeneous, which indicates that their uniformity is most likely not the consequence of their length. The extremities of the scale are consistent across the other panels of Figure 1, viz. they are not primarily informed by document length. As a general note, the ranking of the documents' uniformity based on their full length is preferable to the ranking in the fourth panel of Figure 1 as limiting the data is a trade-off: it limits the effect of the different lengths of the documents, but it does create artificial documents. As Andersen and Forbes argue (1986, 206):

The desire to make fine-grained assertions would lead one to divide the document into myriad chunks. But the smaller a piece, the less compelling any statistical assertions made about it will tend to be, since such assertions will be based on limited data. A trade-off between delicacy of analysis and level of confidence in statistical results must be made.

Certain differences between the panels of Figure 1 can be explained by insight into the mechanics of feature selection and the consequences it has on the quantification of the variation. The precise settings used with these methods affects the outcome. If documents are sampled by randomly selecting only a very limited selection of tokens to avoid a bias due to document length, this puts documents with many idiosyncratic spellings, but with low document frequencies (such as those found in the book of Job), at a disadvantage as the likelihood of selecting two spellings of a profile with only very few occurrences is affected by the lexical richness of the document (Baayen 2008, 32426). The average uniformity based on a limited, randomly sampled document is hence too sensitive for all documents, but it is useful for verifying whether the shortest documents are more uniform solely because of their limited length.

The choice whether to include spellings which are unique to a given document for the computation of other documents' uniformity is important: not using a document frequency to filter the features under scrutiny would entail that the presence of unique variants in a single variety would affect the overall uniformity of documents that contain the profile without the specific variant. In the latter case, the presence of a unique spelling instance in a single document increases the uniformity of other documents. ${ }^{13}$ The restriction that a variant should be found in at least two documents, a setting that is obviously dependent on the number of documents in the corpus, is a good baseline to obtain an interesting set of widely distributed, yet sufficiently flexible unique spelling

12 Regarding the bisection of 1 QIsa ${ }^{\mathrm{a}}$, cf. footnote 9.

13 One might be tempted to remove profiles which are fully homogeneous, but that would create different feature sets for the analyses of the different books, a situation which is not ideal. 
variations that paint the picture of the overall variation in our corpus. The initial analysis presented in Figure 1 on the leftmost panel remains insightful.

These methodological issues go beyond the present analysis. In fact, any analysis which depends on counting linguistic features in ancient Hebrew is likely to face these questions to a certain degree. In this case, the linguistic features are spelling instances, but the same caveats hold for other linguistic features. An alternative is not to take document boundaries as a priori facts. Andersen and Forbes (1986, 205-13), for instance, start their analysis with the laborious and challenging step of redefining document boundaries. Not only is this not always desirable (should the Twelve Prophets be treated as a single document?), it is also a process that is influenced by the objectives one seeks to achieve, hence it is not theory-neutral. The analysis presented here is hence a starting point for related analyses that might shed new light on both the methods to measure orthographic variation, as well as the phenomenon of variation itself.

\section{Discussion}

In our measurement of orthographic uniformity the scrolls stand out at both ends of the spectrum: not only the least, but also the most uniform documents are the ancient ones, and not the medieval copies of the Hebrew Bible which have had a far more extensive transmission history over time. This dichotomy is noteworthy. The fact that the spelling of 1 QIsa ${ }^{a}$ lacks uniformity is commonly accepted in the literature, but it should be highlighted how much it differs from the other scrolls. This is not a consequence of the two scribal hands that are often recognised in the document, because even when 1 QIsa ${ }^{a}$ is split in two, the two parts are still distinctively heterogeneous. The lack of uniformity could in effect be even higher given the fact that the document frequency filter $(\geq 2)$ might exclude other idiosyncratic variants in the document.

The spelling of the Hebrew Bible as presented in the digital edition of the Codex Leningradensis is relatively uniform. It is possible that the transmission of the text witnessed a particular attention to the harmonisation of its spelling, but likewise it could be claimed that the spelling was only updated very infrequently as many heterogeneous, minority variants survived. Was there really no attention to consistency as is sometimes suggested (Tov 2015, 36)? In these cases, quantifying the data does not settle the debate, but it does provide the groundwork that can complement cumulative evidence on these issues based on philology, paleography, and archaeology. At this point, any theory that tries to explain the data, but does not integrate text-critical, source-critical, and philological data is bound to conjectures.

There are multiple confounding factors that influence the measurement and interpretation of orthographic uniformity. If the late Persian period witnessed a gradual increase in the use of vowel letters, for instance, it could be assumed that this transition towards the systematic and abundant use of vowel letters would yield more uniform spellings only when the transition was largely complete, and not in the course of the 
transition itself. While writers and copyists were still transitioning towards a fuller spelling, one could assume that the profiles alternated between defective and full variants, yet when that transition was complete, one would assume that spellings became more uniform unless there was a reason (for instance, archaic or archaising language use, cf. Tigchelaar 2018) to deviate from the general tendency. Are core Qumran documents such as 1QS, 1QM, and 11Q19 witnesses to a completed spelling "reform" or, if that word is exaggerated, renewed spelling preferences, or are they witnesses to the sociological diversity found in the corpus? If there is indeed a diachronic increase in the use of vowel letters, as Andersen and Forbes have observed, one could argue that it should correlate with alterations in orthographic variability. Likewise, it should be explained whether a document reflects an author's, a copyist's, or community's spelling practice, or a mixture of these influences. The uniformity of the documents at the homogeneous end of the spectrum also raises the question whether at a certain point in time a careful effort to systematically limit the variation of spelling at the lexical level took place, an effort very much in line with the Masoretes' later attention for minority and majority spellings.

\section{Case Studies}

The spelling index that serves as the basis for our analyses can be used to explore the particularities of each individual document. The uniformity of individual documents can be compared. As a case study, we examine two documents of the same corpus in more detail: First Samuel, which has a heterogeneous spelling, and Joshua, which has a highly uniform spelling. Both documents are narrative documents containing geo-political, social, and religious historiography, and both documents are of relatively comparable length (Joshua counts ca. 15372 tokens, First Samuel 20 303). For our purposes, First Samuel is separated from Second Samuel despite the fact that both documents were transmitted as a single document in order to avoid limiting the total number of documents available for the analysis, and because First Samuel is of a sufficiently large size to figure separately in the dataset.

The mean uniformity across the large sample of profiles is 0.935 for Joshua and 0.87 for First Samuel. Within the Hebrew Bible these differences are substantial, although they might seem minor because of the small numbers. Joshua and First Samuel stand at the extreme opposites of the uniformity scale. How does this translate into their spelling practices when investigated not as an aggregate measure such as the mean, but when inspecting the profiles that lack uniformity? 
Using the parameters described above, the book of Joshua contains 209 profiles, 168 of which are perfectly consistent and 41 which are not uniform. ${ }^{14}$ The varying profiles are, in the case of Joshua, all binary and they represent 607 tokens of the book (of the ca. 15 372). The index can be consulted to identify the profiles that manifest variation in Joshua (those that are perfectly consistent are excluded). This type of summary table is akin to the profile per book that Barr $(1989,212)$ requests in his monograph; it captures the orthographic idiosyncrasies and tendencies of a given document. ${ }^{15}$ It allows for a number of observations. Joshua is indeed very uniform; it has dominant preferential spellings, often even without the presence of a non-preferential variant. This does not mean that Joshua is always consistent: the object marker with a light suffix is not consistent, for instance, with 39 occurrences of אות versus 27 of and there is even a case with a heavy suffix that is surprisingly spelled plene. ${ }^{16}$ Although there are exceptions (ישב as verb qal participle masculine singular in the absolute state with 5 vs. 2 occurrences respectively for ישב and (ישב preferential variants and these preferential variants are not always systematic choices for either a plene or a defective spelling (ארון, גבול vs. איב, or אמר as infinitive construct, etc.). ${ }^{17}$ In Joshua there is slight variation within the spellings of the feminine suffixes, notably with regard to the presence or absence of a ' to link the headword and the suffix, but that variability is not characteristic of all suffixes (in fact, the variability only occurs in a few suffixes). The third masculine suffixes and הו הו are eccentric when compared to the preferred variants, although both occur only a single time. A frequently repeated lexeme that is inconsistently spelled is משפחה when in the plural construct or absolute states which is interesting given the centrality of the concept in Joshua. Finally, Joshua shows variations in its spelling of the first syllable of participles. These are generally not highly frequent, but it seems there was some freedom to choose whether to use a vowel letter in these cases (רוצח, יוצא, יושבי יושב/ישב,עולה), but this freedom does not concern all participles.

In the case of First Samuel, there are 238 profiles that match the selection criteria; 161 are $100 \%$ uniform, and 77 exhibit internal variation affecting 1004 tokens. Whereas one

14 In what follows, the main text of this article uses final letters where expected at the end of the word, although the actual index that is used for these analyses "desofitised" the forms so that differences between final and non-final forms (such as a and do not count as spelling variants (de Joode 2020).

15 The spelling of the proper nouns in the index is an example of the types of profiles that require manual intervention (for instance, רמה and).

16 Joshua's spelling of the direct object marker can be compared with Genesis, for instance. Inspecting the profile of Genesis is insightful because, in contrast to Joshua, Genesis has a clearer preference for את to spell the object marker (with 156 vs. 9) with a light suffix. Yet where Joshua is more uniform in its spelling of the suffixes, Genesis varies frequently in terms of the inclusion or exclusion of the yôd to connect the headword and its suffix and sometimes in terms of the inclusion of the hê on the second masculine singular suffix. Within the Pentateuch the uniformity of the books is relatively close, yet in several analyses Genesis is less uniform than the other documents in the Torah.

17 Cf. Andersen and Forbes (1986) for an analysis of higher spelling abstractions (or types) and their overuse/underuse in specific documents. 
out of five of the available profiles in Joshua contains internal variation, in First Samuel one out of three profiles captures spelling variation. In First Samuel there are three

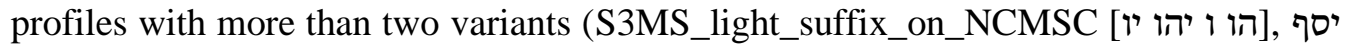

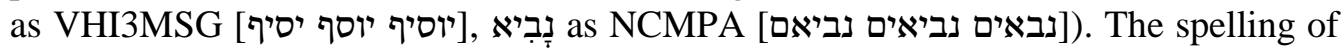
First Samuel is far more heterogeneous than that of Joshua. The variation within the suffixes is relatively limited: most suffixes apart from the third masculine singular suffixes are highly uniform, but there are many relatively low frequency items in the book that are not consistent. It is common to find forms of pairs such as , אפד/אפוד,אויב/איב or or טבים/טובים. The medial vowel letters both in first syllables and in later syllables display far more inconsistency than in Joshua as the use of medial יבאו/יביאו, יבא/יביא ,בא/בוא vowel letters is subject to great variation, for instance יבא/יבוא ,תבא/תבוא. The negative particle לא is primary spelled defectively, but there are 22 cases in which it is spelled fully. First Samuel is far more consistent in its use of את than Joshua (First Samuel spells it 53 times defective and twice full). There are several second masculine singular verb forms which end with he as a vowel letter (מאסתה ,הכיתה, עשיתה). In both First Samuel and Joshua proper nouns are relatively consistent.

The inspection of the profiles containing variation in Joshua and First Samuel for this case study confirms that the aggregate value for orthographic uniformity proposed above captures a difference in spelling variability. This insight now makes it possible to compare and study the way in which documents differ from each other. A final confirmation of the difference between Joshua and First Samuel is the density plot of the distribution of the uniformity of the profiles in each of the books (Figure 3), which highlights how the uniformity values of the profiles are distributed. The density line is a smoothed representation of a histogram. 


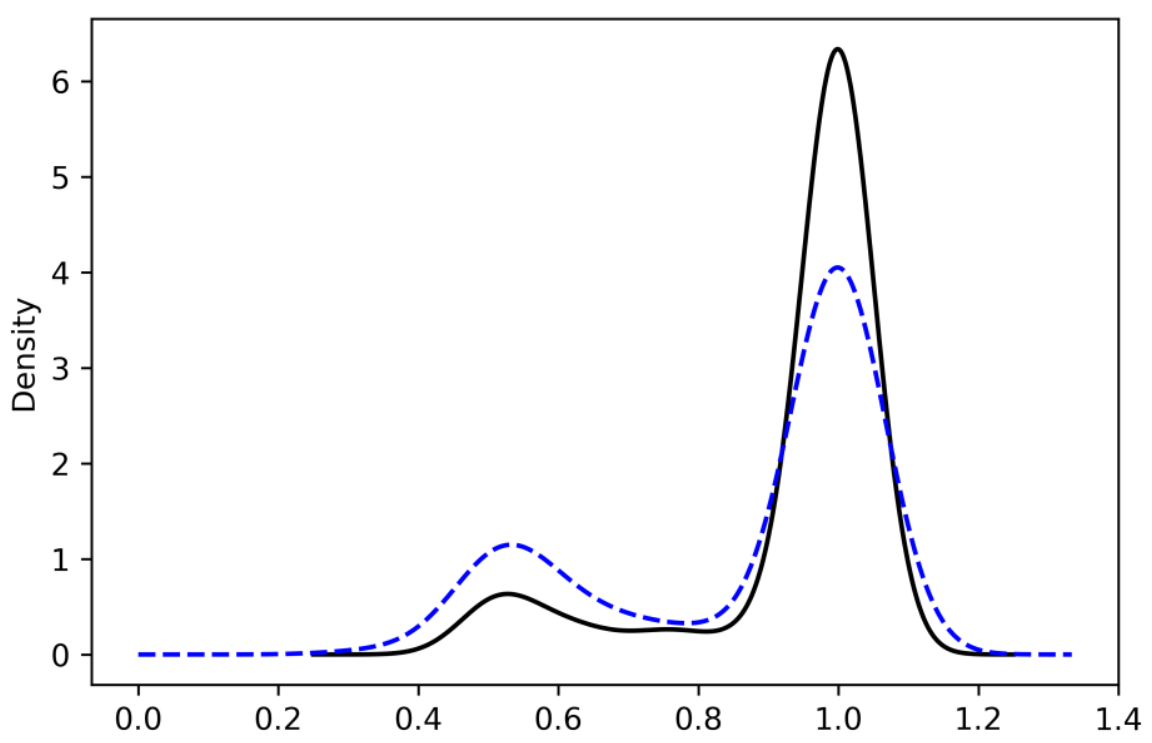

Figure 3: Density plot of the distribution of profile uniformities: First Samuel is represented by a dashed line, Joshua by a solid line

Figure 3 confirms that our method is indeed capturing orthographic uniformity: Joshua's profiles are more uniform as is visible in the "peak" near uniformity $=1$ (which is $100 \%$ uniformity, only a single variant is preferred). The majority of Joshua's profiles have a single variant; the same holds for First Samuel, but the peak is lower and the number of profiles with a lower uniformity are distributed over the dashed line (First Samuel). There are clearer spelling preferences in Joshua, and less clear preferences in First Samuel. As spelling is a social phenomenon (Sebba 2007, 3), a convention or a shared practice, Figure 3 enlightens us about the different transmission histories of the documents. It goes beyond the scope of this article, but the text-critical history of Samuel has been the subject of intense scholarly debate. The inspection of the profiles and the density plot confirm that the document-internal uniformity measure captures uniformity well even if it is applied to all the extracted spelling variation and not only a selection.

These examples illustrate two principles underlying this analysis. Firstly, spelling variation at the lexical level should be investigated at scale. To date, many descriptions of documents and their orthography are impressionistic: they fail to frame the discussion of manually selected, individual variants in a larger framework of a document's overall variability. Scholarly research tends to focus on explaining the causes of spelling variation and describing its implicit rules. If one were to look only at a few cases such as, which is fully uniform in both in Genesis and Joshua, or את with a light suffix 
which is more uniform in Genesis (0.896) than it is in Joshua (0.516), the results would not be reliable. The risk of taking only a small number of profiles is that these profiles might not capture the actual variation, but rather might be the consequence of confirmation bias. Secondly, these case studies illustrate the importance of examining individual spelling profiles and documents. Each document contains a unique set of varying profiles and the profiles of one book should not a priori be taken into account for the computation of the uniformity of another book. There are, for instance, several profiles which occur in the book of Genesis, but which cannot be found in Joshua, which is why we have quantified orthographic variability within the boundaries of individual documents.

Our main issue has been to identify and quantify the overall tendencies. Nonetheless, it is an interesting question to evaluate what motivates deviations from majority spellings. In Exod 19:19, for instance, one could wonder whether the non-preferential spellings used in a short sequence are intentional to mimic that the "sound of the trumpet grew louder and louder" (NASB): ויהי קול השופר הולך וחזק מאד. In this case, the spelling is almost iconic in nature: the plene spellings of the words support their vocal rendering. This is a case of stylistic orthography, and while this specific case is not described by Barr, he does draw attention to the stylistic use of spelling in his conclusion (Barr 1989, 194). There are, of course, many other causes that could trigger an alternative spelling within the boundaries of a specific document, such as those investigated by Andersen and Forbes, including stress, or abstract spelling type, or it is possible that the choice for a particular variant is unmotivated. More analysis of the factors that trigger spelling variation is required.

\section{Conclusion}

This study set out to quantify orthographic uniformity in a corpus of Classical Hebrew composed of the larger books of the Hebrew Bible and the Dead Sea Scrolls (excluding the medieval copy of the Damascus Document). It has been shown that computational and quantitative linguistic techniques can be used to gain insight into the variability of the documents under scrutiny. We have presented a measure for spelling uniformity that is based on an automatically extracted spelling index. This index made it possible to transform spelling counts per book into a profile-document matrix which captures the variation in the corpus, in each profile, but also in each individual document at hand. This matrix was subsequently transformed into matrices with relative frequencies and document frequencies. Each of these respective matrices served to limit the total number of profiles for the analysis of variability. Based on these data we computed the mean consistency at the lexical level per document in our corpus.

The present contribution raised the following questions. How variable are documents when the consistency of their spelling is measured at the lexical level within a single document (and not at the level of morphemes across the entire corpus)? Is the uniformity of the two available corpora comparable? Our analyses have shown that spelling 
variation occurs in all documents, although in different degrees. A series of analyses has shown that while many documents exhibit a relatively large orthographic consistency, the Hebrew Bible and the Dead Sea Scrolls differ in their homogeneity: the Dead Sea Scrolls stand out at both ends of the spectrum of orthographic variability. Several key scrolls such as 1QS, 1QM, and 11Q19 display high degrees of uniformity. At the other end of the spectrum again the scrolls stand out with $1 \mathrm{QIsa}^{\mathrm{a}}$ which displays the most heterogeneous orthographic practice attested in all the documents under scrutiny both when 1QIsa ${ }^{a}$ is treated as a single manuscript and when it is split in two based on the hypothesis that multiple scribal hands can be found in the manuscript. Several of the documents found near the Dead Sea exhibit a uniformity that is greater than that found in the Masoretic text. Although this result could be influenced by the size of the documents as longer documents are more likely to repeat lexical items and therefore to contain variation, an experiment showed that $1 \mathrm{QM}$ and $1 \mathrm{QS}$ are indeed more uniform than other documents regardless of their length. Within the Hebrew Bible, a case study has shown that First Samuel has a highly heterogeneous spelling and Joshua a more uniform one. We have not ventured to claim what caused these corpus-internal divergences, although text-critical advances on the composition history and the transmission of First Samuel could prove valuable.

The study of internal uniformity raised in this paper is likely to advance the study and understanding of the linguistic features of the documents as they developed and were transmitted over time. This approach complements alternative approaches to spelling variation which focus on discerning whether full or defective spellings dominate a document and whether any features predict the choice for either of these spellings. This paper has used an initial dataset. A larger, peer-reviewed dataset should be designed for future studies. Four additional avenues for future research can be identified. Firstly, it would be insightful to obtain quantifications for the orthographic variability in other ancient corpora of related Semitic languages. Millard (1990; 1991) extends Barr's observations to other Semitic languages and, based on epigraphic evidence, he claims that Hebrew is no exception: a similar amount of variability is attested in other ancient corpora. Millard's insights rely primarily on qualitative observations and not on rigid quantification.

Secondly, one can wonder to what extent orthography can be imitated. In the context of the discussion of specific orthographic practices in the Dead Sea Scrolls, Tigchelaar $(2010,204)$ suggests "can we go further and ask, hypothetically, whether [the scribes] expressed their attitude towards those texts by writing them in "biblical" orthography? Was spelling, at least for some scribes, part of the strategies of authorization?" Concerning the book of Job, Seow $(2011,83)$ argues that its conservative orthography "in fact proves nothing of the book's provenance." He also claims that "the text may be not so much archaic, as Freedman would have it, as it is archaistic," thus highlighting the possibility that documents imitate archaic orthographies (Seow 2011, 68). Can one assume that scribes intentionally chose between archaic spellings and updating them in view of more recent practices? How is it possible that for scrolls found in each other's 
vicinity the divergence in spelling practice as measured in terms of uniformity is so substantial? These questions can help to increase our understanding of how documents came into being and how they were transmitted.

Thirdly, if it is accepted that spelling is a social phenomenon, one could wonder to what extent orthographic variability and spelling choice could be used to re-evaluate theories about the social groups that crafted and transmitted the texts. As Tigchelaar claims,

Written language, however, is not simply a record of spoken language. For example, orthography is not simply a conventionalized code enabling reading and writing, but a highly visible domain in which standards can be established or contested. Thus, a shift towards a plene writing in many texts, or a conservative, more defective orthography in other texts, all preserved in the same collection, is not merely a linguistic phenomenon, but requires a sociolinguistic explanation. (Tigchelaar 2018, 206)

Finally, for the Masoretic text it is now possible to investigate the relationship between the conscious notes regarding orthography in the Masoretic apparatus and the actual spelling practices as attested in the documents. This comparison could be elaborated with the study of later debates on spelling in talmudic writings (Martín-Contreras and Miralles-Maciá 2014). In that sense, orthographic variability is likely to provide more insight into spelling practice in ancient times and in the transmission process of the ancient biblical documents and the medieval codices.

\section{References}

Andersen, F. I., and A. D. Forbes. 1986. Spelling in the Hebrew Bible: Dahood Memorial Lecture. Biblica et Orientalia 41. Rome: Biblical Institute Press.

Baayen, R. H. 2008. Analyzing Linguistic Data: A Practical Introduction to Statistics Using R. Cambridge: Cambridge University Press. https://doi.org/10.1017/CBO9780511801686

Barr, J. 1989. The Variable Spellings of the Hebrew Bible: The Schweich Lectures of the British Academy 1986. Oxford: Oxford University Press for the British Academy.

Daems, J., E. Zenner, and D. Geeraerts. 2016. "Lexicale homogeniteit en lexicale voorkeur in de Nederlandse woordenschat van emoties." Tijdschrift voor Nederlandse Taal- en Letterkunde 132 (4): 276-319.

de Joode, J. 2020. "Digital Masorah: Toward an Index of Orthographic and Morphological Variation at the Lexical Level." Journal for Semitics 29 (1): \#6632. https://doi.org/10.25159/2663-6573/6632

Geeraerts, D., S. Grondelaers, and D. Speelman. 1999. Convergentie en divergentie in de Nederlandse woordenschat: een onderzoek naar kleding-en voetbaltermen. Amsterdam: Meertens Instituut. 
Giese, R. L. 1988. "Further Evidence for the Bisection of 1QIs a." Textus 14 (1): 61-70. https://doi.org/10.1163/2589255X-01401006

Martín-Contreras, E., and L. Miralles-Maciá. 2014. Text of the Hebrew Bible: From the Rabbis to the Masoretes. Journal of Ancient Judaism. Supplements 13. Göttingen: Vandenhoeck \& Ruprecht. https://doi.org/10.13109/9783666550645

Millard, A. R. 1990. "Book Review: The Variable Spellings of the Hebrew Bible." Journal for Theological Studies 41 (2): 571-75. https://doi.org/10.1093/jts/42.1.106

Millard, A. R. 1991. "Variable Spelling in Hebrew and Other Ancient Texts." Journal for Theological Studies 42 (1): 106-15.

Qimron, E. 1986. The Hebrew of the Dead Sea Scrolls. Harvard Semitic Studies 29. Atlanta: Scholars' Press. https://doi.org/10.1163/9789004370050

Rahlfs, A. 1916. "Zur Setzung der Lesemütter im Alten Testament.” Nachrichten von der Königlichen Gesellschaft der Wissenschaften zu Göttingen, philologisch-historische Klasse 1916: 315-47. Accessed April 1, 2020. https://archive.org/details/nachrichten1916akaduoft.

Reymond, E. D. 2014. Qumran Hebrew: An Overview of Orthography, Phonology, and Morphology. Resources for Biblical Study 76. Atlanta: SBL. https://doi.org/10.2307/j.ctt5vjz09

Reymond, E. D. 2018. "The Scribe of 1QS, 1QSa, 1QSb, 4Q53 (4QSam"), 4Q175 and Three Features of Orthography and Phonology." Dead Sea Discoveries 25 (2): 238-54. https://doi.org/10.1163/15685179-12341467

Sebba, M. 2007. Spelling and Society: The Culture and Politics of Orthography around the World. Cambridge: Cambridge University Press. https://doi.org/10.1017/CBO9780511486739

Seow, C. L. 2011. “Orthography, Textual Criticism, and the Poetry of Job.” Journal of Biblical Literature 130 (1): 63-85. https://doi.org/10.2307/41304188

Speelman, D., S. Grondelaers, and D. Geeraerts. 2003. "Profile-based Linguistic Uniformity as a Generic Method for Comparing Language Varieties." Computers and the Humanities 37 (3): 317-37. https://doi.org/10.1023/A:1025019216574

Tigchelaar, E. J. C. 2010. “Assessing Emanuel Tov's ‘Qumran Scribal Practice'.” In The Dead Sea Scrolls: Transmission of Traditions and Production of Texts, edited by S. Metso, H. Najman and E. Schuller, 173-207. Studies on the Texts of the Desert of Judah 92. Leiden: Brill. https://doi.org/10.1163/ej.9789004185845.i-274.60 
Tigchelaar, E. J. C. 2018. "Sociolinguistics and the Misleading Use of the Concept of AntiLanguage for Qumran Hebrew." In The Dead Sea Scrolls and the Study of the Humanities Method, Theory, Meaning: Proceedings of the Eighth Meeting of the International Organization for Qumran Studies (Munich, 4-7 August, 2013), edited by P. B. Hartog, A. Schofield and S. I. Thomas, 195-205. Studies on the Texts of the Desert of Judah 125. Leiden: Brill. https://doi.org/10.1163/9789004376397_011

Tov, E. 2004. Scribal Practices and Approaches Reflected in the Texts Found in the Judean Desert. Studies on the Texts of the Desert of Judah 54. Leiden: Brill. https://doi.org/10.1163/9789047414346

Tov, E. 2008. "The Variable Spellings of the Hebrew Bible (Review).” In Hebrew Bible, Greek Bible, and Qumran: Collected Essays, edited by E. Tov, 3-20. Texts and Studies in Ancient Judaism 121. Tübingen: Mohr Siebeck. https://doi.org/10.1628/978-3-16-151454-8

Tov, E. 2015. "Some Reflections on Consistency in the Activity of Scribes and Translators." In Textual Criticism of the Hebrew Bible, Qumran, Septuagint: Collected Essays Volume 3, edited by E. Tov, 36-45. Supplements to Vetus Testamentum 167. Leiden: Brill. https://doi.org/10.1163/9789004285569_004

Ulrich, E. 1990. "Orthography and Text in 4QDan ${ }^{\mathrm{a}}$ and 4QDan ${ }^{\mathrm{b}}$ and in the Received Masoretic Text." In Of Scribes and Scrolls: Studies on the Hebrew Bible, Intertestamental Judaism, and Christian Origins Presented to John Strugnell on the Occasion of His Sixtieth Birthday, edited by Harold W. Attridge, John J. Collins and Thomas H. Tobin, 29-42. College Theology Society Resources in Religion 5. Lanham: College Press of America.

Zahn, M. M. 2018. "Beyond 'Qumran Scribal Practice': The Case of the Temple Scroll." Revue de Qumran 29 (2): 185-203.

Zevit, Z. 1980. Matres Lectionis in Ancient Hebrew Epigraphs. Cambridge, MA: American Schools of Oriental Research. 